Am J Prev Med. 2018 September ; 55(3): 290-297. doi:10.1016/j.amepre.2018.04.035.

\title{
The Potential to Reduce Falls and Avert Costs by Clinically Managing Fall Risk
}

\author{
Judy A. Stevens, $\mathrm{PhD}^{1}$ and Robin Lee, PhD, $\mathbf{M P H}^{2}$ \\ ${ }^{1}$ Advanced Technology Logistics Inc., Control, Centers for Disease Control and Prevention, \\ National Center for Injury Prevention and Control. 4770 Buford Highway, Atlanta, GA 30341 \\ ${ }^{2}$ Control, Centers for Disease Control and Prevention, National Center for Injury Prevention and \\ Controll. 4770 Buford Highway NE, Atlanta, GA 30341, USA
}

\begin{abstract}
INTRODUCTION—Falls often cause severe injuries and are one of the most costly health conditions among older adults. Yet, many falls are preventable. The number of preventable medically treated falls and associated costs averted were estimated by applying evidence-based falls interventions in clinical settings.
\end{abstract}

DESIGN-A peer-review literature review was conducted in 2017 using literature published between 1994 and 2017, the authors estimated the prevalence of seven fall risk factors and the effectiveness of seven evidence-based falls interventions.

PARTICIPANTS-Older Americans aged 65 and older living in the community.

INTERVENTIONS-Tai chi, Otago, medication management, vitamin D supplementation, expedited first eye cataract surgery, single vision distance lenses for outdoor activities, and home modifications led by an occupational therapist.

MEASURES-The authors estimated the number of older adults who would be eligible to receive one of seven falls interventions. Then, using the reported effectiveness of each intervention, the number of medically treated falls that could be prevented and the associated direct medical costs averted was calculated.

RESULTS-Depending upon the size of the eligible population, implementing a single intervention could prevent between 9,563-45,164 medically treated falls and avert \$94-\$442 million in direct medical costs annually. The interventions with the potential to help the greatest number of older adults were those that provided home modification delivered by an occupational therapist (\$38.2 million), and recommended daily vitamin D supplements (\$16.7 million).

Corresponding author: Robin Lee, PhD MPH, Team Lead - Home and Recreational Injury Prevention, Centers for Disease Control and Prevention, National Center for Injury Prevention and Control, 4770 Buford Highway NE, Mailstop F-62, Atlanta, GA 30341, RLee3@cdc.gov, Phone: 770-488-3811, Fax: 770-488-1317.

Financial and other Conflicts of Interests Disclosure: The authors have no conflicts of interest or financial disclosures to disclose. Sponsor's Role: No external funding was received for this work. 
CONCLUSIONS-This report is the first to estimate the number of medically treated falls that could be prevented and the direct medical costs that could be adverted. Preventing falls can benefit older adults substantially by improving their health, independence, and quality of life.

\section{Keywords}

Elderly; falls; falls intervention; health care provider; medical cost

\section{Introduction}

Falls among people 65 and older can be traumatic, resulting in injuries, decreased mobility, and loss of independence. ${ }^{1}$ In 2015, more than 28,000 older adults died and 3.0 million more were treated in emergency departments for nonfatal fall injuries. ${ }^{2}$ In 2015 , total medical expenditures for falls totaled $\$ 50$ billion, making falls one of the most costly health conditions among people 65 and older. ${ }^{3,4}$

A fall risk factor is an attribute or characteristic of an individual that increases the likelihood of a fall occurring. Many fall risk factors are potentially modifiable (e.g., poor balance, mobility problems, impaired vision, insufficient vitamin D). ${ }^{5}$ A contributing factor adds to the chances of a fall. Contributing factors include side effects of specific medications and the presence of home hazards. An early study by Tinetti et al. found that fall risk increased linearly with the number of risk factors present. ${ }^{6}$ Conversely, reducing these risks reduces a person's chances of falling.

Although research is limited, data have shown that there are a number of effective falls interventions designed for community-dwelling older adults that can be incorporated into clinical care settings, such as modifying medications and recommending vitamin D supplements to older adults who have a vitamin D insufficiency. ${ }^{7,8}$ In addition, health care providers can address other fall risk or contributing factors by referring patients to:

- Community-based programs to improve poor balance (e.g., Tai chi), ${ }^{9}$

- Physical therapists to correct mobility problems, ${ }^{10}$

- Ophthalmologists to improve vision, ${ }^{11,12}$ and

- Occupational therapists to help modify unsafe behaviors and reduce home hazards (e.g., clutter). ${ }^{13}$

Over $90 \%$ of older adults see a medical provider at least once a year, ${ }^{14}$ which gives clinicians the opportunity to inform and empower older adults to address one or more specific risk factors to reduce their chances of falling. Individualized clinical fall risk assessment and treatment is recommended in the American and British Geriatrics Societies' clinical practice guidelines. ${ }^{15}$ However, few health care providers are aware of or feel confident implementing these clinical guidelines. ${ }^{16-18}$

It was hypothesized that if more health care providers were aware of and chose to implement a clinical fall prevention program-including screening for fall risk, assessing potential risk factors, and implementing evidence-based treatment strategies-it would be possible to 
decrease the fall rate among America's increasing older population and advert sizable health care costs. This analysis examined the prevalence of seven modifiable fall risk or contributing factors among United States (US) community-dwelling adults aged 65 and older and the potential savings in injuries and health care costs through targeted falls interventions.

\section{Methods}

A two-step process was used to calculate the population-level impact of seven evidencebased interventions on reducing falls and lowering direct medical costs among communitydwelling older adults. The first step was to use the most current prevalence data from the peer-reviewed literature, which ranged from 1994-2017 depending on the factor, and the current US Census to estimate the number of older adults with specific fall risk or contributing factors and the proportion of these adults eligible for clinical interventions. ${ }^{19}$ The literature review was conducted in 2017.

Table 1 presents the fall risk or contributing factors addressed in this analysis (Column A). These include:

1. Poor balance due to neurological gait disorders ${ }^{20}$

2. Mobility problems ${ }^{21}$

3. Medication use potentially linked to falls 22

4. Vitamin D insufficiency $(<50 \mathrm{ng} / \mathrm{ml})^{23}$

5. Visual impairment caused by cataract ${ }^{24}$

6. Poor depth perception due to the use of multifocal eyewear ${ }^{25,26}$

7. Home hazards ${ }^{27}$

The first step was to estimate the number of older adults with each of the above factors (Column B). This was done by multiplying the prevalence of the factor (Column A) by 47.8 million, the number of community-dwelling adults aged 65 and older in the US. in 2014. ${ }^{19}$

The next step used the Centers for Disease Control and Prevention's $3^{\text {rd }}$ Compendium of Effective Fall Interventions: What Works for Community-Dwelling Older Adults to identify seven evidence-based clinical interventions that could be used to reduce or manage the identified risk factors. ${ }^{28}$ The compendium describes randomized control trials published in the peer-reviewed literature between 1994 and 2014. Each trial demonstrates the ability to reduce falls among community-dwelling older adults. The Compendium includes interventions that address single risk factors as well as multifactorial interventions that address multiple risk factors. For the purpose of this analysis, interventions that focused on a single risk factor were selected. The seven interventions include (Column C):

1. Tai chi exercise program

2. Otago Exercise Program by a physical therapist

3. Medication management 
4. Vitamin D supplementation

5. Expedited first eye cataract surgery

6. Single vision distance lenses for outdoor activities

7. Home modifications led by occupational therapist

Column $\mathrm{C}$ also shows the effectiveness of each intervention in reducing falls over one year. When available, the effectiveness of the intervention was based on the results of metaanalyses of multiple randomized controlled studies. ${ }^{7,} 9,10,13$ When no meta-analyses was available, the effectiveness was based on a single randomized study. $8,11,12$

Column D shows the type of older adults who would be eligible for the intervention and Column E shows the proportion of older adults who would be eligible for the intervention. This is important since not all interventions were effective for all older adults. For example, all persons 65 and older with vitamin D insufficiency would be eligible for vitamin D supplementation. However, among those with vision impairment due to uncorrected refractive errors, the study found that only active adults who participated in outdoor activities were likely to benefit from single vision distance lenses.

To calculate the total population eligible for each intervention (Column F), the number of older adults with the risk factor (Column B) was multiplied by the percentage of older adults eligible for the intervention (Column E). If only a subset of older adults with the risk factor were eligible, data from the National Health and Nutrition Examination Survey and the National Health Interview Survey was used to estimate the percent eligible in Column E. 29,30

Older adult adoption and adherence to community-based falls interventions can vary greatly depending on the characteristics of the population, (e.g., older age, socioeconomic status, perceived benefits, health status, presence fall risk factors), the type of intervention (e.g., home-based exercise program, medication withdrawal, or home modification), and logistical considerations (e.g., distance the participant would have to travel, potential out of pocket expenses). ${ }^{31-35}$ Therefore, to calculate the total eligible population that was likely to participate and adhere to the intervention, it was assumed conservatively that $10 \%$ of people who were eligible for an intervention would adopt it. Therefore, the total eligible population (Column F) was multiplied by $10 \%$ to reflect the number of eligible older adults likely to adopt the intervention (Column G).

In step two, the expected number of falls was calculated, assuming the intervention was not implemented (Column $\mathrm{H}$ ). This was done by multiplying the total eligible population (Column F) by $28.7 \%$, (the national incidence of self-reported falls ${ }^{36}$ ) and multiplying the result by $1,000,000$. The number of falls the intervention could prevent (Column I) was estimated by multiplying the expected number of falls (Column $\mathrm{H}$ ) by the effectiveness of the intervention (Column C).

National data suggest that about $37.5 \%$ of reported falls result in either injury or restricted activity. ${ }^{36}$ Therefore the number of medically treated falls prevented (Column J) was calculated by multiplying the number of falls prevented with the intervention (Column I) by 
$37.5 \%$, recognizing that this provided an overestimate because some falls with minor injury or restricted activity typically go untreated.

Lastly, the direct medical costs averted (in millions) annually with the intervention (Column $\mathrm{K}$ ) were calculated by multiplying the number of medically treated falls prevented (Column J) by $\$ 9,780$, (the average cost of a medically treated fall ${ }^{37}$ ), and dividing by $1,000,000$.

\section{Results}

Table 1 shows the estimated number of falls prevented and direct medical costs averted with selected interventions among community-dwelling older adults in the US. Columns A and B show the prevalence of seven fall risk or contributing factors and the number of older adults with the factor: poor balance due to vestibular disorders, mobility problems, medication use potentially linked to falls, vitamin D insufficiency, visual impairment from cataract, poor depth perception due to use of multifocal eyewear, and home hazards. Column $\mathrm{C}$ presents the interventions and intervention effectiveness for each specific factor. Columns D through $\mathrm{G}$ describe the target population for each evidence-based falls intervention and provide an estimate of the number of older adults who would receive each intervention, and Columns $\mathrm{H}$ through $\mathrm{J}$ show the expected number of falls, estimated number of falls prevented, number of medically treated falls prevented, and direct medical costs averted.

The impact of each intervention depends on both the level of effectiveness and the number of eligible people receiving it. Although the costs averted are presented for the portion of the population with each factor, both poor balance and mobility problems could be addressed through referrals to Tai chi programs or the Otago Exercise Program provided by a physical therapist, increasing the total potential in direct medical savings.

Because of the high prevalence and large eligible population, addressing home hazards with the assistance of an occupational therapist would prevent the greatest number of medically treated falls $(45,164)$ and avert the most in direct medical costs $(\$ 442$ million). The next highest savings would result by expediting first eye cataract surgery ( $\$ 423$ million), reviewing and managing medications ( $\$ 418$ million), treating mobility problems regardless of underlying health status ( $\$ 409$ million), improving poor balance regardless of fall history (\$363 million), correcting vitamin D insufficiency (\$247 million), and improving depth perception by using single vision distance lenses for outdoor use (\$237 million).

\section{Discussion}

This study examined seven fall risk or contributing factors and seven specific falls interventions for community-dwelling adults aged 65 and older. The potential for reducing falls and averting the associated direct medical costs was striking. Based on the size of the eligible population and the effectiveness of the intervention, it was estimated that between 9,563 and 45,164 medically treated falls could be prevented annually. The associated costs to Medicare averted ranged from $\$ 94$ million to $\$ 442$ million, depending on the targeted risk or contributing factor, the size of the eligible population, and the effectiveness of the intervention. 
Having multiple fall risk factors increases an individual's chances of falling, such as when an older adult with poor balance and impaired vision encounters a tripping hazard. ${ }^{6}$ Poor balance may be addressed through a fall prevention program such as the Otago Exercise Program while visual impairment due to cataracts may be treated surgically. However, estimating the cost averted from interventions that addressed multiple risk factors is not easily calculated. To do so would require national prevalence estimates for the proportion of the population with the specific risk factors of interest. In addition, the effectiveness of studies that address single risk factors cannot simply be added together to estimate an overall effect. Some interventions may have a greater or multiplicative affect while others may have no effect. Further research is needed to estimate the extent of these interdependencies and whether implementing multiple interventions would yield equal or greater cost benefits.

Health care providers are well positioned to implement evidence-based clinical interventions such as those described in this analysis. Clinical interventions, such as reviewing and managing medications, are within the purview of health care providers and are typically conducted during regular office visits. Similarly, reviewing vitamin D intake and recommending vitamin D supplements can be addressed with standard medication review and management.

Health care providers also can play an important role by identifying prevalent modifiable risk factors among their older patients and referring them to specialists such as optometrists or ophthalmologists for uncorrected visual problems, and pharmacists for medication review and management. Finally, providers could refer patients to community-based interventions, including Tai chi and the Otago Exercise Program, and for home modification delivered by occupational therapists.

Incorporating fall prevention into clinical care presents a number of challenges although it can be implemented successfully. ${ }^{38-40}$ Implementation requires modifying the workflow, training staff to conduct falls risk assessments, and incorporating key elements of the process into electronic health record systems. Health care providers must also decide whether to focus on a specific modifiable risk factor or on multiple risk factors. Addressing multiple risk factors has shown to reduce the rate of falls by up to $24 \% .{ }^{9}$ However, clinical judgment and patient preferences must be considered to ensure that patients follow through with the recommended strategy.

This analysis was based on a number of assumptions. First, although the prevalence of specific risk and contributing factors in the older population used data published in peerreviewed publications, not all were based on national estimates. Therefore, prevalence estimates may have been over or underestimated. In addition, national prevalence estimates were not available for all risk factors. Therefore proxy measures were used for some risk factors. For example, there is no US based prevalence of poor balance. Therefore a population-based Italian study that reported the prevalence of gait disorders was used to estimate the prevalence of poor balance in older Americans. This study found neurologic gait disorders were associated with recurrent falls. This is a conservative estimate given neurological gait disorders are one of many causes of poor balance among older adults. Similarly, the intervention described by Haran et al compared the use of bifocal lenses to 
single focal lenses for people who ambulate outside the home. ${ }^{11}$ Given there is no national prevalence of older adults who wear bifocals, a proxy estimate was calculated using nationally representative date from the National Health and Nutrition Examination Survey. These data were reported by two different studies. The proportion of adults age 50 and older who use eyewear to correct for near vision impairment (87.5\%) and the proportion of adults who use eyewear for distance vision correction (41\%). ${ }^{25,}{ }^{26}$ Given vision impairment increases with age these estimates are likely conservative estimates of the actual prevalence of multifocal use among adults 65 and older.

A strength of this study is that intervention effectiveness for four interventions was based on the results of meta-analyses. ${ }^{7,9,10,13}$ Because meta-analyses include multiple studies with differing levels of effectiveness, the summary estimates we used were conservative. Metaanalyses were not available for three interventions. ${ }^{8,11,12}$ Therefore the effectiveness estimates were based on single studies of specific populations, (e.g., first cataract surgery among older women) ${ }^{12}$ For these interventions, effectiveness may have been over or under estimated.

While adoption rates differ by intervention, we chose to use $10 \%$ for all interventions. This allowed for uncertainly and the fact that there is always some amount of participant attrition. We also assumed adoption would be the same for all community-dwelling older adults regardless of population characteristics or their logistical considerations. Additional research is needed to determine how to encourage older adults to adopt and adhere to fall prevention strategies. Developing tailored promotion strategies could improve adoption rates and result in more falls prevented and higher costs adverted.

The calculations for this study did not take into account the cost of implementing the interventions. These costs would vary widely depending on the type of intervention (e.g., cataract surgery versus a Tai Chi exercise program) and the implementation setting. Carrying out a community fall prevention program comes with numerous costs including instructor training, transportation, and facility use expenses. While a cost-benefit analysis of Tai Chi: Moving for Better Balance and the Otago Exercise Program showed that these two programs were cost effective ${ }^{41}$ more research is needed to evaluate the cost-benefit in implementing the other interventions described in this paper.

\section{Conclusions}

This analysis, which used conservative estimates based on the peer-reviewed literature, showed that fall interventions delivered by US health care providers have the potential to prevent thousands of falls among older adults, thereby improving their health and wellbeing. In addition, implementing these interventions could substantially lower health care costs for Medicare.

Health care providers are in a unique position to educate and empower their older patients to reduce falls. In addition, the passing of the Medicare Access and Chip Reauthorization Action of 2015 incentivizes providers to screen for falls and conduct fall risk assessments and interventions, such as those described by the Centers for Disease Control and 
Prevention's (CDC) STEADI (Stopping Elderly Accidents, Deaths, and Injuries) initiative. 42, 43 STEADI includes resources and tools to help members of the health care team (e.g., physicians, nurses, pharmacists, physical therapists) integrate falls prevention into their clinical practice (www.cdc.gov/STEADI). Specifically, STEADI describes procedures for screening patients for fall risk, identifying their modifiable fall risk factors, and applying effective strategies to reduce their multiple fall risk factors (Figure 1). Providers such as those at the Oregon Health and Science University (OHSU) and the United Health Services in New York have been successfully using STEADI ${ }^{38-40}$ For example, OHSU providers were able to screen $64 \%$ of eligible patients in six months and intervene to reduce risk in $85 \%$ of community-dwelling older adults with gait impairment, $97 \%$ with orthostatic hypotension, $82 \%$ with vision impairment, $90 \%$ with inadequate vitamin D intake, $75 \%$ with foot issues, and $22 \%$ taking high-risk medications. ${ }^{40}$ Additional research is underway to examine the number of falls and the cost effectiveness of these efforts to address multiple risk factors among older patients. When put into practice, clinical fall prevention efforts such as STEADI could prevent falls and help America's older adult population live safe, healthy, and independent lives.

\section{Acknowledgments}

CDC Disclaimer: The findings and conclusions in this report are those of the authors and do not necessarily represent the official position of the Centers for Disease Control.

Author Contributions: Each author contributed to the study design, data analysis, interpretation of the data, and to the preparation of manuscript.

Financial and other Conflicts of Interests Disclosure: No funding was received to conduct this study. The authors have no conflicts of interest or financial disclosures to disclose.

\section{References}

1. Sterling DA, O'Connor JA, Bonadies J. Geriatric falls: Injury severity is high and disproportionate to mechanism. J Trauma. 2001; 50(1):116-9. [PubMed: 11231681]

2. Centers for Disease Control and Prevention (CDC). [Accessed May 10, 2017] Web-based Injury Statistics Query and Reporting System (WISQARS). www.cdc.gov/ncipc/wisqars

3. Dieleman JL, Baral R, Birger M, Bui AL, Bulchis A, Chapin A, et al. US spending on personal health care and public health, 1996-2013. JAMA. 2016; 316(24):2627-2646. [PubMed: 28027366]

4. Florence CS, Bergen G, Atherly A, Burns E, Stevens J, Drake C. Medical Costs of Fatal and Nonfatal Falls in Older Adults. J Am Geriatr Soc. 2018

5. Rubenstein LZ. Falls in older people: Epidemiology, risk factors and strategies for prevention. Age Ageing. 2006; 35(Suppl 2):ii37-ii41. [PubMed: 16926202]

6. Tinetti ME, Speechley M, Ginter SF. Risk factors for falls among elderly persons living in the community. N Engl J Med. 1988; 319(26):1701-7. [PubMed: 3205267]

7. Murad MH, Elamin KB, Abu Elnour NO, Elamin MB, Alkatib AA, Fatourechi MM, et al. Clinical review: The effect of vitamin D on falls: A systematic review and meta-analysis. J Clin Endocrinol Metab. 2011; 96(10):2997-3006. [PubMed: 21795448]

8. Pit SW, Byles JE, Henry DA, Holt L, Hansen V, Bowman DA. A Quality Use of Medicines program for general practitioners and older people: A cluster randomised controlled trial. Med J Aust. 2007; 187(1):23-30. [PubMed: 17605699]

9. Gillespie LD, Robertson MC, Gillespie WJ, Sherrington C, Gates S, Clemson LM, et al. Interventions for preventing falls in older people living in the community. Cochrane Database Syst Rev. 2012; 9:CD007146. 
10. Thomas S, Mackintosh S, Halbert J. Does the 'Otago exercise programme' reduce mortality and falls in older adults?: A systematic review and meta-analysis. Age Ageing. 2010; 39(6):681-687. [PubMed: 20817938]

11. Haran MJ, Cameron ID, Ivers RQ, Simpson JM, Lee BB, Tanzer M, et al. Effect on falls of providing single lens distance vision glasses to multifocal glasses wearers: VISIBLE randomised controlled trial. BMJ. 2010; 340:c2265. [PubMed: 20501583]

12. Harwood RH, Foss AJ, Osborn F, Gregson RM, Zaman A, Masud T. Falls and health status in elderly women following first eye cataract surgery: a randomised controlled trial. Br J Ophthalmol. 2005; 89(1):53-9. [PubMed: 15615747]

13. Karlsson MK, Vonschewelov T, Karlsson C, Coster M, Rosengen BE. Prevention of falls in the elderly: A review. Scand J Public Health. 2013; 41(5):442-54. [PubMed: 23554390]

14. O’Hara B, Caswell K. [Accessed August 3, 2017] Health Status, Health Insurance, and Medical Services Utilization: 2010. Current Population Reports. www.census.gov/prod/2012pubs/ p70-133.pdf. Published 2013

15. Panel on Prevention of Falls in Older Persons, American Geriatrics Society and British Geriatrics Society. Summary of the updated American Geriatrics Society/British Geriatrics Society clinical practice guideline for prevention of falls in older persons. J Am Geriatr Soc. 2010; 59(1):148-57.

16. Chou WC, Tinetti ME, King MB, Irwin K, Fortinsky RH. Perceptions of physicians on the barriers and facilitators to integrating fall risk evaluation and management into practice. J Gen Intern Med. 2006; 21(2):117-22. [PubMed: 16336618]

17. Fortinsky RH, Iannuzzi-Sucich M, Baker DI, Gottschalk M, King MB, Brown CJ, et al. Fall-risk assessment and management in clinical practice: views from healthcare providers. J Am Geriatr Soc. 2004; 52(9):1522-6. [PubMed: 15341555]

18. Rubenstein LZ, Solomon DH, Roth CP, Young RT, Shekelle PG, Chang JT, et al. Detection and management of falls and instability in vulnerable elders by community physicians. J Am Geriatr Soc. 2004; 52(9):1527-31. [PubMed: 15341556]

19. U.S. Census Bureau. [Accessed August 3, 2015] Population estimates. www.census.gov. Published 2014

20. Mahlknecht P, Kiechl S, Bloem BR, Willeit J, Scherfler C, Gasperi A, et al. Prevalence and burden of gait disorders in elderly men and women aged 60-97 years: a population-based study. PLoS One. 2013; 8(7):e69627. [PubMed: 23894511]

21. Courtney-Long EA, Carroll DD, Zhang QC, Stevens AC, Griffin-Blake S, Armour BS, et al. Prevalence of disability and disability type among adults--United States, 2013. MMWR Morb Mortal Wkly Rep. 2015; 64(29):777-83. [PubMed: 26225475]

22. Zhan C, Sangl J, Bierman AS, Miller MR, Friedman B, Wickizer SW, et al. Potentially inappropriate medication use in the community-dwelling elderly: Findings from the 1996 Medical Expenditure Panel Survey. JAMA. 2001; 286(22):2823-9. [PubMed: 11735757]

23. Looker AC, Johnson CL, Lacher DA, Pfeiffer CM, Schleicher RL, Sempos CT. Vitamin D status: United States, 2001-2006. NCHS Data Brief. 2011; (59):1-8.

24. NIH National Eye Institute. [Accessed Febuary 13, 2018] US Age-Specific Prevalence Rates for Cataract by Age, and Race/Ethnicity. https://nei.nih.gov/eyedata/cataract/tables. Published 2010

25. Vitale S, Cotch MF, Sperduto R, Ellwein L. Costs of refractive correction of distance vision impairment in the United States, 1999-2002. Ophthalmology. 2006; 113(12):2163-70. [PubMed: 16996610]

26. Zebardast N, Friedman DS, Vitale S. The Prevalence and Demographic Associations of Presenting Near-Vision Impairment Among Adults Living in the United States. Am J Ophthalmol. 2017; 174:134-144. [PubMed: 27865728]

27. Carter SE, Campbell EM, Sanson-Fisher RW, Redman S, Gillespie WJ. Environmental hazards in the homes of older people. Age Ageing. 1997; 26(3):195-202. [PubMed: 9223715]

28. Centers for Disease Control and Prevention (CDC). [Accessed May 10, 2017] A CDC

Compendium of Effective Fall Interventions: What Works for Community-Dwelling Older Adults. https://www.cdc.gov/homeandrecreationalsafety/falls/compendium.html. Published 2015 
29. Agrawal Y, Carey JP, Della Santina CC, Schubert MC, Minor LB. Disorders of balance and vestibular function in US adults: Data from the National Health and Nutrition Examination Survey, 2001-2004. Arch Intern Med. 2009; 169(10):938-44. [PubMed: 19468085]

30. Blackwell DL, Lucas JW, Clarke TC. Summary health statistics for U.S. adults: National Health Interview Survey, 2012. Vital Health Stat. 2014; 10(260):1-161.

31. Campbell AJ, Robertson MC, Gardner MM, Norton RN, Buchner DM. Psychotropic medication withdrawal and a home-based exercise program to prevent falls: A randomized, controlled trial. J Am Geriatr Soc. 1999; 47(7):850-3. [PubMed: 10404930]

32. Day L, Fildes B, Gordon I, Fitzharris M, Flamer H, Lord S. Randomised factorial trial of falls prevention among older people living in their own homes. BMJ. 2002; 325(7356):128. [PubMed: 12130606]

33. Farrance C, Tsofliou F, Clark C. Adherence to community based group exercise interventions for older people: A mixed-methods systematic review. Prev Med. 2016; 87:155-166. [PubMed: 26921655]

34. Forkan R, Pumper B, Smyth N, Wirkkala H, Ciol MA, Shumway-Cook A. Exercise adherence following physical therapy intervention in older adults with impaired balance. Phys Ther. 2006; 86(3):401-10. [PubMed: 16506876]

35. Picorelli AM, Pereira LS, Pereira DS, Felicio D, Sherrington C. Adherence to exercise programs for older people is influenced by program characteristics and personal factors: A systematic review. J Physiother. 2014; 60(3):151-6. [PubMed: 25092418]

36. Bergen G, Stevens MR, Burns ER. Falls and fall injuries among adults aged $>/=65$ years - United States, 2014. MMWR Morb Mortal Wkly Rep. 2016; 65(37):993-998. [PubMed: 27656914]

37. Burns ER, Stevens JA, Lee R. The direct costs of fatal and non-fatal falls among older adults United States. J Safety Res. 2016; 58:99-103. [PubMed: 27620939]

38. Casey CM, Parker EM, Winkler G, Liu X, Lambert GH, Eckstrom E. Lessons learned from implementing CDC's STEADI falls prevention algorithm in primary care. Gerontologist. 2016; Epub published ahead of print. doi: 10.1093/geront/gnw074

39. Stevens J, Smith M, Parker E, Jiang L, Floyd F. Implementing a clinically based fall prevention program. Am J Lifestyle Med. 2017; Epub published ahead of print. doi: $10.1177 / 1559827617716085(0)$

40. Eckstrom E, Parker E, Lambert H, Winkler G, Dowler D, Casey CM. Implementing STEADI in Academic Primary Care to Address Older Adult Fall Risk. Innov Aging. In Press.

41. Carande-Kulis V, Stevens JA, Florence CS, Beattie BL, Arias I. A cost-benefit analysis of three older adult fall prevention interventions. J Safety Res. 2015; 52:65-70. [PubMed: 25662884]

42. Stevens JA, Phelan EA. Development of STEADI: A fall prevention resource for health care providers. Health Promot Pract. 2013; 14(5):706-14. [PubMed: 23159993]

43. Lee R. The CDC's STEADI Initiative: Promoting older adult health and independence through fall prevention. Am Fam Physician. 2017; 96(4):221. 


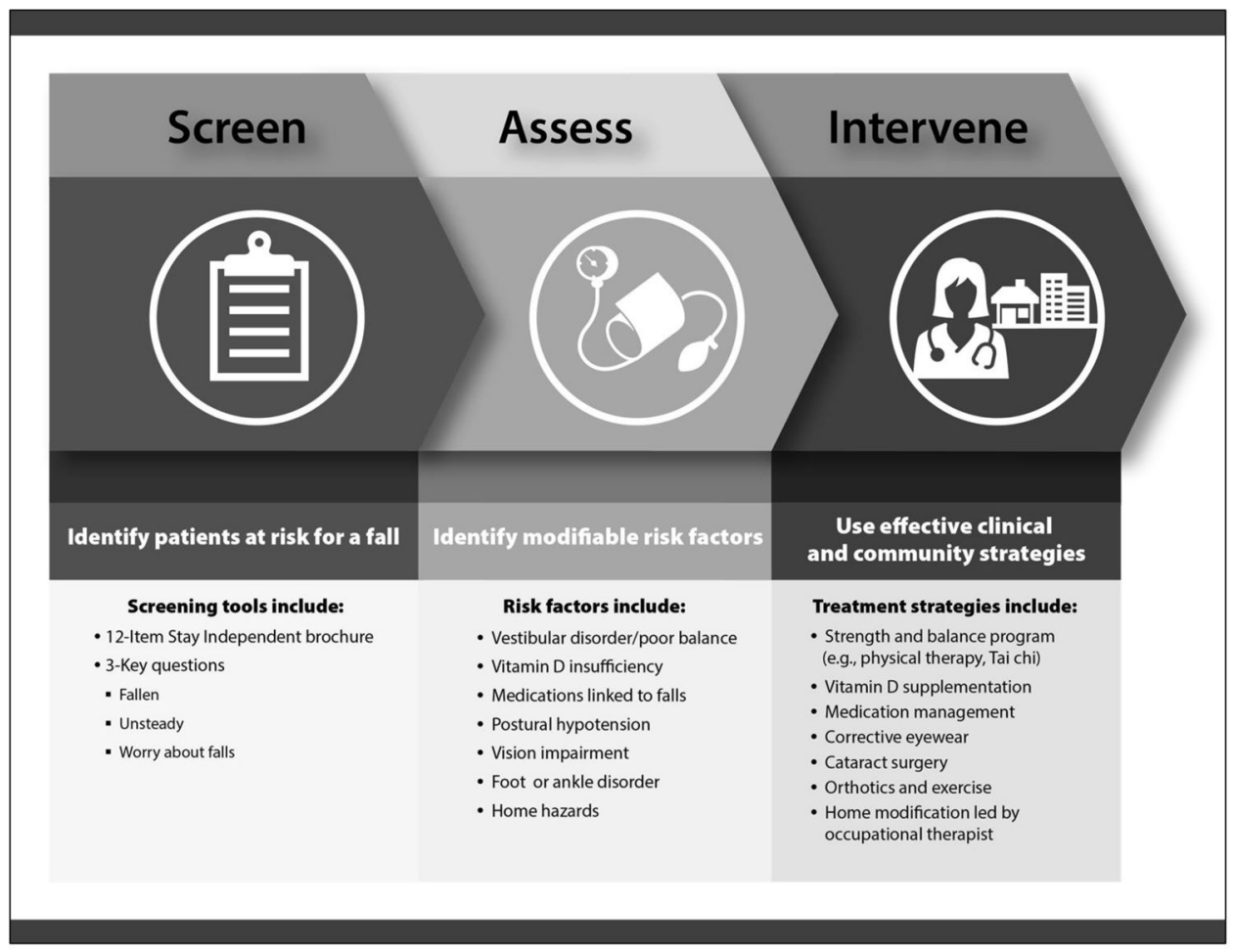

Figure 1.

The STEADI Initiative

The CDC STEADI Initiative represents a coordinated approach to implementing the American and British Geriatrics Societies' clinical practice guidelines for fall prevention. STEADI includes three core elements: screening, assessment, and intervention to reduce fall risk. 


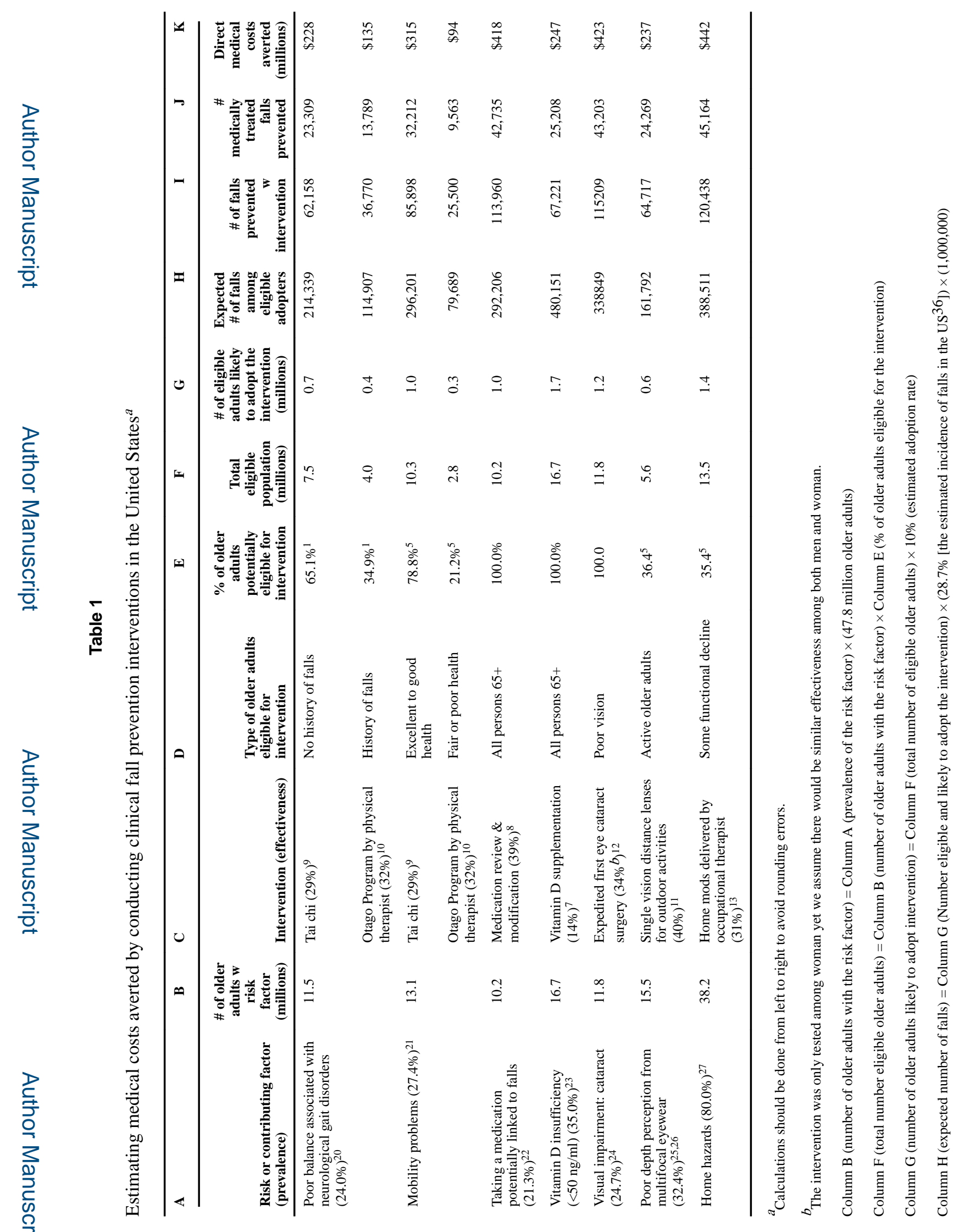

Am J Prev Med. Author manuscript; available in PMC 2019 September 01. 


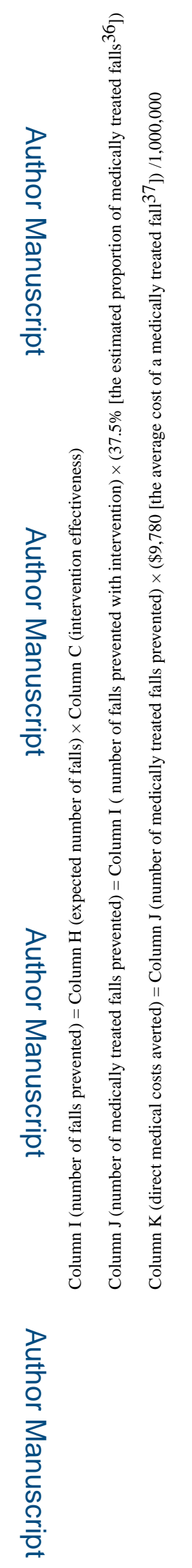

Am J Prev Med. Author manuscript; available in PMC 2019 September 01. 